\section{Claude Lévi-Strauss e o mito da mitologia}

Claude LÉVI-STRAUSS. O homem nu. Mitológicas $I V$. Trad. Beatriz Perrone-Moisés. São Paulo, Cosac Naify, 2011. 752 páginas.

\section{Messias Basques}

A publicação deste volume encerra o projeto de tradução da tetralogia do antropólogo francês Claude Lévi-Strauss, permitindo aos leitores brasileiros o acesso à íntegra dessa monumental sinfonia em quatro atos, as Mitológicas. Falecido no mês de novembro de 2009, às vésperas de completar 101 anos, Lévi-Strauss foi um dos grandes pensadores do século XX. O que o encantava em autores como Jean de Léry era a maneira especial de descrever as memórias de viagem com um olhar particular que transportaria o leitor, como em um passe de mágica, para outro tempo e espaço. As Mitológicas são, justamente, uma viagem pelo universo mítico ameríndio, um itinerário no qual a obra de Lévi-Strauss mantém uma relação de fundo com a sua própria trajetória pessoal. Se o ponto de partida do primeiro volume (O cru e o Cozido, 2004 [1964]) foi um mito do povo indígena Bororo, habitantes do Brasil Central, sobre um certo desaninhador de pássaros em torno do tema da "conquista da cultura", agora somos conduzidos à América do Norte. Percurso este que foi realizado em vida por Lévi-Strauss, que conheceu de perto vários povos indígenas no Brasil, iniciando-se dessa maneira na etnografia, e que também se notabilizou por seu minucioso trabalho de pesquisa em arquivos e bibliotecas norte-americanos. Durante os anos de exílio, a estada em Nova York rendeu-lhe a convivência com os surrealistas André Breton e Marcel Duchamp, entre outros, além de um acontecimento decisivo: o contato com o linguista Roman Jakobson.

Nas Mitológicas, a transição de um hemisfério ao outro do continente se dá em movimentos espiralados - "progressões em rosáceas" -, onde se avança à medida que se amplia o diálogo mitológico orquestrado pelo autor. Embora tenha dito que odiava as viagens e os exploradores, as Mitológicas de Claude Lévi-Strauss propóem um convite aos leitores para que embarquem em uma jornada que só pode se realizar como um mito da mitologia, isto é, a condição de possibilidade de uma obra como esta é a sua composição aos modos de um mito, como uma versão cujos eixos temáticos privilegiados são necessariamente arbitrários - pois se poderia começar de quaisquer outros pontos -, mas ancorados em questôes consideradas comuns aos 813 mitos ameríndios reunidos na tetralogia, tais como a passagem da natureza à cultura, o estabelecimento de regras de aliança e a separação entre humanos e não humanos. Nas palavras de François-René de Chateaubriand, autor de Viagem à América (1827), e que aparecem citadas em epígrafe ao capítulo "Junções", das Mitológicas: "Por mais diversos que sejam os caminhos, os viajantes chegam ao ponto de encontro."

Afinal, por que povos tão afastados, da América do Sul e do Norte, puderam elaborar narrativas que se conectam em tantos pontos? Os mitos, dirá Lévi-Strauss, se pensam entre si ao mesmo tempo em que pensam a sociedade de onde provêm, com a ressalva de que jamais pertencem a uma única sociedade, pois o que é mais próprio deles é viajar por entre elas e, assim, transformarem-se. Ressoa nesta tese uma afirmação de Franz Boas, antropólogo que lhe foi contemporâneo e responsável pela organização de um imenso material dedicado à mitologia dos povos norte-americanos: "Dir-se-ia que os universos mitológicos são destinados a ser pulverizados mal acabam de se formar, para que novos universos nasçam de seus fragmentos." Se pensar é viajar, o que os mitos têm a dizer não se esgota em suas sociedades de origem, posto que produzem "aberturas", vias alternativas para que se possam vislumbrar as operaçôes mais fundamentais do intelecto humano. Aqui, portanto, pensar a partir de outrem é viajar pelo pensamento mítico ameríndio. A diretriz dessa viagem refere-se ao método de análise estrutural do mito, desenvolvido por Claude Lévi-Strauss, segundo o qual um mito não tem começo nem fim, pois nada mais seria do que um fragmento de uma narrativa maior. $\mathrm{O}$ seu sentido não está contido jamais em si mesmo, mas deve ser buscado em outros relatos, muitas vezes em povos diferentes, onde poderá ser (re)encontrado de maneira transformada.

Se no primeiro volume, a dicotomia básica é o cru e o cozido, o segundo volume (Do mel às 
cinzas, 2005 [1967]) trata da oposição entre o mel e o tabaco. $\mathrm{O}$ mel aparece ligado à ideia de natureza e o tabaco ao mundo sobrenatural. Ambos os volumes são voltados às metáforas culinárias na representação dessas passagens, sendo que no primeiro se trata da aquisição da cultura, e no segundo os mitos narram a sua perda e a regressão à natureza. De um lado, a conquista do fogo de cozinha, dos ornamentos, da carne de caça e das plantas cultivadas; de outro, a perda do mel cultivado para as abelhas e as árvores, da carne de caça, das artes da civilização e até mesmo das categorias lógicas. No terceiro volume ( $A$ origem dos modos à mesa, 2006 [1968]), somos levados às planícies da América do Norte através do fio condutor de um mito amazônico, analisado em seus aspectos formais, textuais, etnográficos e semânticos. Se os mitos dos dois primeiros volumes operam com oposições espaciais (alto e baixo, céu e terra, sol e humanidade), as narrativas norte-americanas reunidas no terceiro volume operam oposições temporais (lento e rápido, duração igual ou desigual, dia e noite), enquanto encenam uma reflexão sobre a moral em termos do comportamento humano e em analogia com os fenômenos cósmicos, astronômicos e meteorológicos. A culinária reaparece como uma tecnologia da mediação, que permite a passagem entre esses operadores binários, como do cru ao cozido. Depende dessas tecnologias, do xamanismo e dos rituais, sobretudo, o cuidado e a manutenção de uma ordem cósmica ou mesmo da condição humana - que se poderia dizer "temperada", assim como um instrumento musical afinado, em equilíbrio.

Entusiasta do movimento surrealista, Claude Lévi-Strauss sentia-se à vontade com Max Ernst e Paul Delvaux, tendo recebido deste último uma ilustração para o quarto volume das suas Mitológicas. Contudo, o efeito que o texto causou no artista foi inesperado, já que sua ilustração é antes de tudo realista: um homem nu subindo em uma árvore. A imagem de um homem nu, tal como discutida por Lévi-Strauss, retrata a conversão do código culinário em código vestimentar, o que se pode verificar na mitologia dos povos habitantes da região noroeste da América do Norte, entre os rios Klamath e Frazer, caso se siga a pista do mito bororo do desaninhador de pássaros que ali se encontra transformado. Isto é, na passagem da categoria de $c r u$ para a de $n u$, a cultura se associa menos à origem da culinária do que à do vestuário. Noutro episódio, relatado por um mito chilcotin, o herói entrelaça as penas encontradas em um ninho e seus próprios cabelos para improvisar um casaco contra o frio. $\mathrm{O}$ que pode isso querer dizer, pergunta-nos Lévi-Strauss, a não ser que o herói, descrito como dono de belas roupas, conserva uma conotação ligada ao vestuário, ainda que, no estado de nudez em que se encontra no topo da árvore ou do penhasco, só esteja vestido sob o disfarce da natureza? A longa cabeleira, vestimenta natural, opõe-se assim às roupas manufaturadas como o cru se opõe ao cozido, confirmando novamente a passagem de um código ao outro.

Lévi-Strauss irá demonstrar que o mito do desaninhador de pássaros, que narra a origem do fogo, é a versão atenuada de um grupo de transformações passível de ser encontrado de Norte a Sul do Novo Mundo. Os protagonistas de todo esse "campo mítico" compõem um "mito único" e estão ligados entre si por uma relação de afinidade matrimonial: os humanos, de um lado, e um povo celeste que detém o fogo, de outro. Em linhas gerais, o fogo, que é o fundamento da cultura, apresenta-se como correspondente da aliança, o fundamento da sociedade. No Prólogo, delimita-se a região que parece estar entre as de ocupação mais antiga e regular do continente - as costas brumosas dos estados de Washington e da Colúmbia Britânica -, fornecendo a contextualização geográfica, arqueológica e etnográfica do conteúdo das narrativas. Dividido em sete partes, $\mathrm{O}$ Homem $\mathrm{Nu}$ faz a costura entre a mitologia dos gêmeos (e da gemelaridade) e a mitologia da afinidade (e do incesto) que se estrutura em torno do desaninhador de pássaros, motivo mítico que reaparece ora em forma literal, ora transfigurado na América do Norte. Este é o ponto que abre a primeira parte do volume, "Segredos de família", cujo escopo se refere a desavenças familiares e a alianças perigosas, como no caso dos desejos incestuosos, em variantes combinatórias perceptíveis em narrativas que relatam a transformação de personagens humanos em animais, tal a ave mergulhadora nos mitos de Dona Mergulhão. 
Na segunda parte, “Jogo de ecos”, Lévi-Strauss explora os operadores binários mel-tabaco, adornos-carne em face do código culinário com o objetivo de demonstrar suas ressonâncias mitológicas e um desequilíbrio dinâmico no seio do grupo das transformações, quando o sal surge como paradoxo de uma culinária crua, a única capaz de levar o alimento ao seu ponto de perfeição, mas por efeito de vias naturais. $\mathrm{Na}$ outra ponta do grupo, em compensação, o tabaco, que corresponde simetricamente ao mel ou ao sal, aparece ao mesmo tempo como obra da cultura e meio supremo de comunicação com o mundo sobrenatural. Não se trata apenas de ecos, dirá o autor, mas propriamente de um jogo de espelhos cujo efeito faz com que dois sistemas míticos consideravelmente afastados (em termos geográficos) se reproduzam um ao outro, não obstante as transfiguraçôes decorrentes da estrutura de cada uma das superfícies refletoras, diferentes em cada caso. A história de Dona Mergulhão apresenta-se como mito de origem do fogo, ao passo que a história do desaninhador de pássaros, que lhe é simétrica, se manifesta no hemisfério sul do continente como mito da origem da água.

Chegamos à terceira parte, "Cenas da vida privada”, cuja epígrafe de Honoré de Balzac já antecipa as desventuras que resultam de comportamentos indevidos: avós transformadas em animais, glutonas, vivendo em estado de libertinagem ou na iminência de relações incestuosas. Em contrapartida, surgem assim a renovação periódica das geraçôes, como a impossibilidade de rejuvenescer ou ressuscitar, ao mesmo tempo em que aparece uma periodicidade biológica, que condiciona a procriação. Dona Mergulhão apresenta-se como uma criatura sazonal, que oscila perpetuamente entre três planos: a cultura (do ponto de vista estético e do vestuário), a sociedade (em suas relaçōes sexuais e nas alianças matrimoniais) e a natureza (por sua carne incomestível, seja por seu gosto ruim, seja por seu caráter sagrado). Lévi-Strauss retoma a questão da dualidade nos mitos klamath e modoc sobre Dona Mergulhão, que nos contam uma história de gêmeos póstumos, primeiro colados e unificados pela avó, que posteriormente se desdobram, para dar lugar a um par de crianças de mesmo sexo ou de sexos diferentes.
O autor se pergunta por que os mitos postulam essa união extrema se, após concluída, a unidade volta a se desdobrar em dualidade, problema que está na base de outro de seus livros, História de Lince (1991), uma de suas "pequenas mitológicas", e que consiste em uma espécie de posfácio aos estudos sobre a mitologia americana desenvolvidos pelo autor durante quatro décadas. Neste livro aparecerá a oposição entre as mitologias indo-europeias e ameríndias da gemelaridade: de um lado, os gêmeos indo-europeus seriam ou totalmente semelhantes ou completamente antagônicos, destacando-se o valor da identidade em detrimento da diferença; de outro, os gêmeos ameríndios tenderiam a uma alteridade relativa, em favor da diferença e atribuindo à identidade um valor maléfico.

"Cenas da vida provinciana", título da quarta parte, refere-se às histórias de feiras intertribais dos povos que ocupavam os grandes locais de pesca no curso inferior do rio Columbia. Numa região da América do Norte onde se vivia mais de pesca do que de caça, e onde não se praticava agricultura, são os mitos da origem dos peixes que se transformam em mitos sobre a origem da troca. Ao instituir a troca, lembra Lévi-Strauss, o demiurgo fixou definitivamente a fronteira entre cultura e natureza, humanidade e animalidade. Aos bens e pessoas que são adquiridos nas feiras e mercados ou em consequência de transações matrimoniais opõe-se uma categoria de riquezas que, como o fogo de cozinha e a água potável, pertencem a todos. O que a variedade dos mitos reunidos neste volume demonstrará é, justamente, uma verdadeira tipologia das modalidades que a vida pode assumir com base nessa oposição fundamental.

$\mathrm{Na}$ quinta parte, "Amargos saberes", o autor volta à região da América do Norte que está entre as de povoamento mais antigo e contínuo, recortada pela dupla barreira das Rochosas a leste e do oceano a oeste. Os registros migratórios em direção à América do Sul instigam-no a investigar, ali, um terreno ideal de comparação entre versôes dos mesmos mitos provenientes de ambos os hemisférios. Novamente, um homem coberto de belas roupas é obrigado, por seu pai, a despir-se, passando assim de dono do fogo a herói nu que treme de frio, como nos conta um mito do povo Nez-Percé. Ao 
norte do rio Columbia, na bacia do Fraser, a história do desaninhador mantém-se inalterada, mas associa o episódio da liberação dos salmôes tanto à questão da repartição dos peixes na rede hidrográfica quanto à da exogamia como propriedade característica da rede de alianças matrimoniais. A leitura e a análise estrutural desse amplo conjunto de mitos norte-americanos se dão em constante contraponto àqueles encontrados no hemisfério sul, que os exprimiam de modo latente, e confirma, segundo Lévi-Strauss, as virtudes do método e a pertinência de seus resultados.

A sexta parte, "Volta às origens", tem início com uma série de variaçôes sobre o tema da origem do fogo e dos salmôes, bem como das condiçôes de sua partilha quando do embate entre os povos do céu e da terra, ocasiāo que também marca o aparecimento de estrelas. Em seguida, discute-se o papel das aves como mediadores temporais que garantem a alternância das estações, além de estarem em relação direta com a origem do fogo (e o aquecimento cultural), a origem da vida breve e a origem da chuva (aquecimento natural). "Aurora dos mitos", a sétima parte do volume, traz uma digressão sobre os operadores binários em torno do tema da taxonomia da vida animal, vendo-os como algoritmos a serviço do pensamento mítico. Lévi-Strauss chega a falar de um "saber oculto" que orienta tais aproximações, embora ressalte a sua diferença em face das taxonomias "mais científicas", como no caso da função semântica do "zoema galináceo" - redutíveis, como os fonemas dos linguistas, a feixes de elementos diferenciais diversamente combinados que denotaria a interseção entre a vida e a morte, e a passagem de uma à outra. Pois nomear, dirá Lévi-Strauss, é classificar e, portanto, introduzir a descontinuidade. Como não ver aí, novamente, uma estreita relação entre o objeto de estudo e os moldes da obra? A possibilidade de chegar a um "mito único" ocorre após um lento e minucioso inventário mitológico que percorre todo o continente, reencontrando na bacia do rio Columbia a origem, primeiro natural e depois social, dos recursos alimentares que permitem aos homens sobreviver.

$\mathrm{Na}$ sétima e última parte, o autor expõe os fundamentos do método da análise estrutural dos mitos e responde a alguns de seus críticos. Aqui se encontra sua conhecida afirmação de que a mitologia diz muito sobre a sociedade sobre a qual provém e sobre o funcionamento do "espírito humano", embora diga pouco sobre a ordem do mundo, a natureza do real, a origem do homem e seu destino. Nada mais controverso, sobretudo ao cabo de uma jornada de fôlego ímpar pelo universo mitológico ameríndio que nos fala, precisamente, de origens e derrocadas, conquistas e catástrofes. Talvez Claude Lévi-Strauss tenha levado às últimas consequências a tese de que as Mitológicas são um "mito da mitologia" e, por isso, a tetralogia não faria mais que nos oferecer vias de entrada, dentre tantas possíveis, ao pensamento ameríndio. Renato Sztutman (O espirito na América, 2005), em ensaio sobre os dois primeiros volumes das Mitológicas, propôs que a fidelidade de Lévi-Strauss à tradição humanista e racionalista o impediu de abandonar por completo a ideia de "espírito humano", ainda que a tenha conduzido até o limite de um "espírito ameríndio", inseminado pelo pensamento destes povos. Nas palavras de Eduardo Viveiros de Castro (A propriedade do conceito, 2001), um de seus mais originais comentadores: "o que os mitos ameríndios dizem - se preferir o leitor, o que eles ensinam - é que não há por que escolher, pois não há como separar, entre a natureza do real e o espírito humano, a ordem do mundo e o movimento da sociedade". Ao orquestrar esta odisseia mitológica, o célebre antropólogo francês inseriu o pensamento destes povos no horizonte da filosofia do Ocidente, um feito incomensurável.
MESSIAS BASQUES é mestre em Antropologia Social pelo PPGAS-UFSCar e fundador e editor responsável pela $\mathrm{R} @ U$ : Revista de Antropologia Social dos Alunos do PPGAS. E-mail: <messias.basques@gmail.com>. 